\title{
A COMPREHENSIVE STUDY OF IOT FOR ALZHEIMER'S DISEASE
}

\author{
Roberto Omar Andrade*, Sang Guun Yoo* and María F. Cazares** \\ *Facultad de Ingeniería de Sistemas, Escuela Politécnica Nacional, Ecuador \\ **Facultad de Ciencias Psicológicas - IDEIAGEOCA, Universidad Politécnica Salesiana, Ecuador
}

\begin{abstract}
The aging process includes the degradation of physical and neurological functions in the people. Although the process of degradation of functions is normal, in some people due to certain risk factors the impact can be high. The appearance of chronic diseases in older adults, one of which is Alzheimer's with about 46.8 million affected worldwide, can affect the quality of life of the person. Alzheimer's at the moment is considered a disease without a cure, an early detection together with an adequate cognitive stimulation can help to reduce the impact for the older adults and their relatives. Ambient Assisted Living - AAL solutions can help the person maintain a quality life, independent and socially active.

The inclusion of ICT (Information Communication and Technology) in AAL solutions increase their functionalities and the higher number of deployments of IoT in recent years and its future projection has generated the interest of its application in different domains of society such as: transport, agriculture and health; however, IoT is a relatively new technology and its development is still in progress. The contribution of this work is present an overview about the use of IoT in patients with Alzheimer's, and make an analyze the use of IoT in the processes of cognitive stimulation considering the possible technical limitations of IoT.
\end{abstract}

\section{KEYWORDS}

IoT, Ambient Assisted Living, Alzheimer's, Cognitive Stimulation

\section{INTRODUCTION}

The concern of health organizations in relation to older adults is based on the population growth of approximately 1 billion of people for every ten years around the world, in the case of the group of people who are more than 65 years old, their growth is more accelerated with a rate of $3 \%$ per year that of young and middle age groups (ONU, 2018). Low birth rates and longer life expectancy are transforming the composition of the world population, with a marked transition towards a much older population structure. Life expectancy for older adults will be 72 in 2020 and this increase to 84 years byN2050 (ONU, 2019). The population of the European Union on January 1, 2017 was estimated at 511.5 million, with a percentage of older people of $19.4 \%$, showing an increase of 0.2 percentage points compared to the previous year and an increase of 2.4 percentage points compared to 10 years earlier.

With the process of aging since of 65 years of age, the nervous system and the brain suffer certain degradation that can generate neurological problems (Kerchner, 2016), so is important identify the type of disease that can affect the health of older adult (NCSC, 2019). In the Table 1, we show the most common neurological disorders associated with aging according to World Health Organization (HWO, 2019). 
Table 1. Neurological disease associated with aging

\begin{tabular}{llcc}
\hline Diseases & \multicolumn{1}{c}{ System } & People-Affected & $\begin{array}{l}\text { Aging } \\
\text { process }\end{array}$ \\
\hline Neuropathy & Nervous system & 30 millon & yes \\
\hline Alzheimer's & Nervous system & 46.8 millon & yes \\
\hline Parkinson & Nervous system & 7 millon & yes \\
\hline Lateral Sclerosis & Nervous system & 2.5 millon & yes \\
\hline Stroke & Nervous system & 15 millon & yes \\
\hline Muscular Dystrophy & Nervous system & 1 millon & yes \\
\hline
\end{tabular}

Alzheimer's disease will could affect to approximately 200,000,000 individuals by the year 2050, and an early diagnosis allows life planning, decision making, and treatment when therapies. The inclusion of ICTs in the medical field has allowed improve the processes of treatment and accompaniment of some diseases for maintain an adequate quality of life for patients (Econsultancy, 2019).

Older adults in some cases live alone in their homes, so they will require remote medical assistance or some mechanism that allow know their health by the medical staff or their family, but also keep the privacy and security of the sensible information (Trendmicro, 2019). This population and health context for the following twenty years drives research into works about proactive and preventive health monitoring assisted by technology in smart domestic environments. The deployment of systems of Ambient Assisted Living (AAL) uses ICTs in the daily life of one older adult persons to enable them to live independently and stay active and socially connected (Medrano, 2018). The market for remote patient control is expected to grow from 10.6 billion in 2012 to 21.2 billion in 2017 (Forbes, 2019). This social and economic growth needs revitalize work on proactive and preventive health monitoring assisted by technology in home environments (Tsirmpas, 2017).

\section{AN OVERVIEW ABOUT ALZHEIMER'S}

Alzheimer's is currently a disease without a cure, and its evolutionary process offers great challenges for patients and their families. The psychological and emotional ramifications of early diagnosis without adequate therapy and resources that allow lead an adequate quality of life can be a frustrating process for the person and relatives. Portellano (2015) reports that the time of evolution of Alzheimer's is 12 years and defines three stages; each stage presents their own alterations and symptoms. The first stage denominated preclinical, with one to three years of duration presents abnormal biomarkers and without or only subtle cognitive impairment. The second stage, mild cognitive impairment is defined as the presence of abnormal pathophysiological biomarkers and episodic memory impairment, this stage has two to ten years of duration. Finally, the third stage called dementia presents abnormal biomarkers, and clear cognitive and functional impairment, this stage has eight to twelve years of duration. In the Table 2 we show the alterations and symptoms associated with each stage.

According to Muñoz (2009), the development of daily activities of people that suffer from deficiency in cognitive processes require the use of various strategies to compensate these losses. For example; devices such as electronic diaries, provide support for immediate memory, for the organization of time and activities, also voice recordings, alarms, key searchers support this cognitive process. 
Table 2. Symptoms stage of Alzheimer's disease (Portellano, 2005)

\begin{tabular}{|c|c|c|c|}
\hline Functions & $\begin{array}{l}\text { First stage - } \\
\text { Preclinical }\end{array}$ & $\begin{array}{l}\text { Second Stage - Mild } \\
\text { Cognitive }\end{array}$ & Third stage - Dementia \\
\hline Memory & $\begin{array}{l}\text { Immediate memory and } \\
\text { fixation memory. } \\
\text { Progressive forgetting } \\
\text { and inability to new } \\
\text { learn. }\end{array}$ & $\begin{array}{l}\text { Severe amnestic disorder, } \\
\text { episodic memory. } \\
\text { They remember more easily } \\
\text { the oldest events, but not } \\
\text { those that have happened } \\
\text { recently }\end{array}$ & None \\
\hline Language & 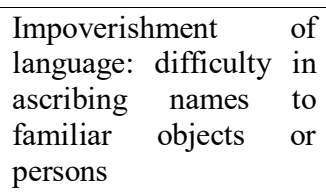 & Initial aphasia & $\begin{array}{l}\text { Transcortical or sensory aphasia. } \\
\text { Alters the symbolic structure of } \\
\text { language, echolalia and palilalia }\end{array}$ \\
\hline Behavior & $\begin{array}{lr}\text { Mood changes } & \text { and } \\
\text { manifestations } & \text { of } \\
\text { apathy, sadness } & \text { and } \\
\text { irritability } & \end{array}$ & $\begin{array}{lr}\text { Conduct } & \text { progressively } \\
\text { indifferent, apathetic and } \\
\text { sometimes } \\
\text { hyperactive } & \text { restless, } \\
\text { hallucinating } & \text { and } \\
& \end{array}$ & $\begin{array}{l}\text { Conduct loss of behavioral } \\
\text { initiative, low tolerance to } \\
\text { frustration, paranoid ideas and } \\
\text { lack of adaptation in their } \\
\text { behaviors, with changing mood } \\
\text { and labile affectivity. } \\
\text { Constructive apraxia and dress } \\
\text { apraxia } \\
\text { ideomotor and ideatory apraxia }\end{array}$ \\
\hline Awareness & $\begin{array}{l}\text { Anosognosia: reduction } \\
\text { of initiative and lack of } \\
\text { awareness of their } \\
\text { disease }\end{array}$ & None & None \\
\hline Executive functions & None & 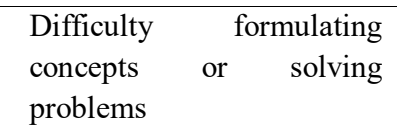 & None \\
\hline Motor skills & None & None & $\begin{array}{l}\text { Generalized afaso-apracto- } \\
\text { agnosico: } \\
\text { gatismo syndrome urinary and } \\
\text { fecal incontinence, muscle } \\
\text { serious deterioration that affects } \\
\text { all areas, total dependence on the } \\
\text { environment, stiffness and flexed } \\
\text { posture. }\end{array}$ \\
\hline
\end{tabular}

\section{IOT SOLUTIONS FOR ALZHEIMER'S}

Deployment and projection of IoT solutions in different domains of society, almost 20 billion of IoT devices by year 2020 worldwide (Forbes, 2018), motivates to researchers and industries consider the use of IoT solutions in the medical field to improve AAL solutions (Mulero, 2018). United Kingdom, for example, implements a IoT-based geographic sensors network to maintain a record of the clinical status of patients and thus avoid that them have to make continuous visits to the hospital. In this study, is our motivation analyze the application of Internet of Things - IoT in the processes of the evolution of Alzheimer's disease.

The research methodology used in this study considers the following steps:

1. Define our research question. What is the use of IoT in those related to Alzheimer's disease?

2. Define the search criteria. "Alzheimer's and IoT", "Alzheimer's and Internet of Things", and "Dementia and IoT".

3. Define the inclusion criteria. We consider the papers presented in scientific bases recognized worldwide as Scopus, IEEE, ACM, and Web of Science, published in the last 4 years (2015-2019). 
4. Define the primary studies. We consider a screening process of two rounds; first we analyze the papers collected based on the title and abstract through a blind review by the authors of this study. The second round is to perform a full text review of the papers collected. From the screening process carried out, to a total of 35 articles were determined.

5. Perform a qualitative analysis of selected papers that will allow us to answer our research question, identifying the use of IoT in Alzheimer's persons. Based on the qualitative analysis made, the applications are mainly focused on the monitoring of patients with Alzheimer's. In the Figure 1, we show density analysis of works related to Alzheimer's and IoT, they are focus on the use of sensors, RFID, and medical/mobile computing for the process of health monitoring and location tracking. There is a relationship between the level of monitoring and the level of dementia of the person.

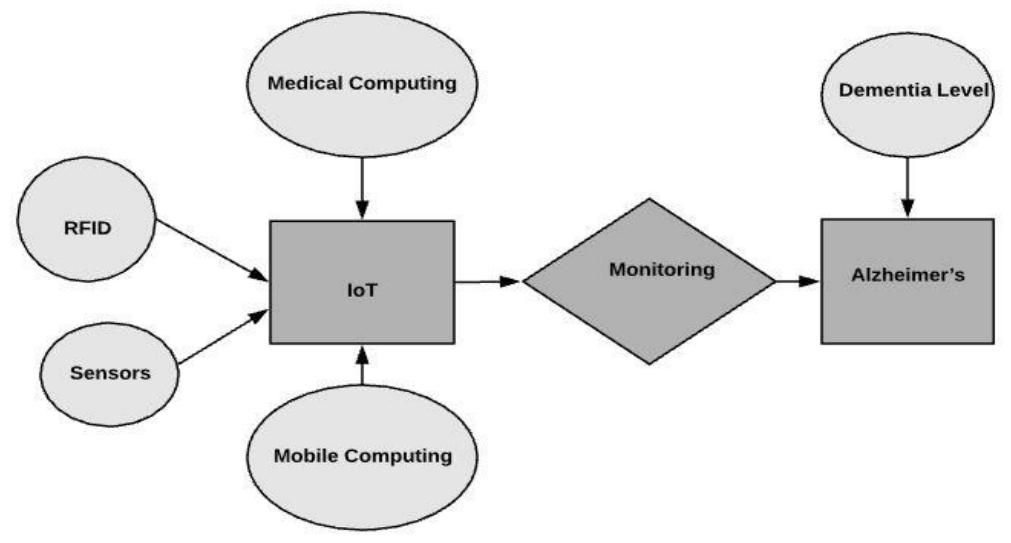

Figure 1. Density of works associated with Alzheimer's and IoT

In the Table 3, we show the IoT-based commercial projects that we have considered most relevant to the support for people with Alzheimer's with a description of their functionality.

Table 3. IoT projects for Alzheimer's disease

\begin{tabular}{|c|c|c|}
\hline Project & Description & References \\
\hline $\begin{array}{l}\text { iCare: the patient with Alzheimer's } \\
\text { must have a portable IoT device, } \\
\text { which is the Apple Smartwatch. The } \\
\text { second part is a download of the iOS } \\
\text { application on the caregiver's iPhone } \\
\text { that must be connected to the } \\
\text { patient's clock }\end{array}$ & $\begin{array}{l}\text { The application allows caregivers to track and find } \\
\text { their loved ones, especially if they go out alone, and } \\
\text { also shows the patient's heart rate to caregivers when } \\
\text { they need it. It has another feature that is the list of } \\
\text { reminders to schedule tasks, such as bathing, exercises, } \\
\text { a patient's medications and medical appointments. In } \\
\text { addition, the application has a section where caregivers } \\
\text { can get information about Alzheimer's disease }\end{array}$ & (Aljehani, 2018) \\
\hline City4Age Project & $\begin{array}{l}\text { Research and innovation project funded by } \\
\text { Horizon } 2020 \text { with the objective of enabling age- } \\
\text { friendly cities. }\end{array}$ & $(\mathrm{EU}, 2019)$ \\
\hline Sphere Project & $\begin{array}{l}\text { Install sensors inside the house of elderly people living } \\
\text { alone. These sensors can detect the behavior by initial } \\
\text { symptoms of dementia. }\end{array}$ & (Zhu, 2015) \\
\hline Timeless & $\begin{array}{l}\text { Application designed to help Alzheimer's patients } \\
\text { recognize their family and friends through facial } \\
\text { recognition. }\end{array}$ & (Timeless, 2019) \\
\hline $\begin{array}{l}\text { ROADMAP "Real-world results } \\
\text { across the spectrum of Alzheimer's } \\
\text { disease for better care: Multimodal } \\
\text { data access platform". }\end{array}$ & $\begin{array}{l}\text { Provide the basis for an integrated data environment } \\
\text { and framework for real-world evidence (RWE in the } \\
\text { Alzheimer's disease). }\end{array}$ & (Roadmap, 2019) \\
\hline $\begin{array}{l}\text { Tweri application: Alzheimer's } \\
\text { Caregiving. }\end{array}$ & $\begin{array}{l}\text { Application that uses GPS technology to detect } \\
\text { Alzheimer's patients. }\end{array}$ & (Tweri, 2019) \\
\hline
\end{tabular}


Based on the comparison between the functionalities of the commercial solutions and the developments in the academic field, there is a difference in the objective of the proposals. In the academic field, IoT has been mostly used to develop monitoring solutions, while commercial solutions are mainly focused on cognitive reinforcement. An important gap to be consider in research field is find solutions for cognitive stimulation of Alzheimer's people, especially at the present time with the broad development of IoT, BigData and Machine Learning.

\section{COGNITIVE STIMULATION USING IOT FOR ALZHEIMER'S}

Alzheimer's is a disease without a cure but is possible make compensatory interventions to reduce the losses associated with cognitive processes, the Figure 2 shows some of the techniques that can be used for this objective. Regarding external aid the use of ICTs and specifically in related to this study IoT can be considered as a tool to improve its effectiveness. The combination of IoT with machine learning could be considered to improve the cognitive reinforcement in the related with metacognitive and specific skills training.

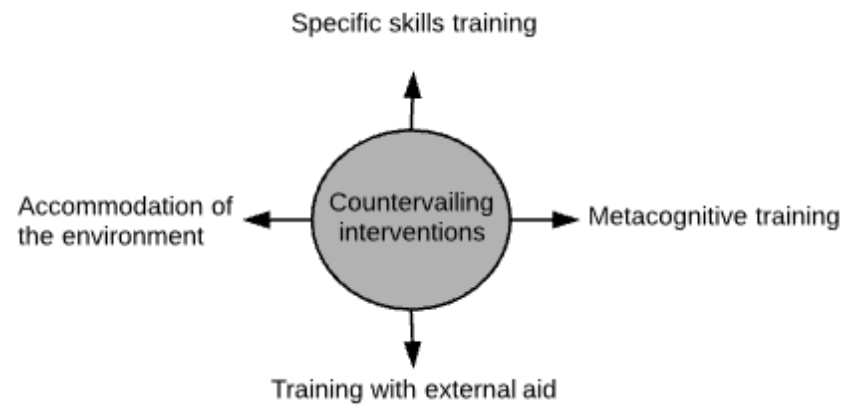

Figure 2. Interventions for cognitive stimulation

From the literature review in this study some points that we have considered relevant are the use of cognitive stimulation using fuzzy adaptive (Navarro, 2018), the use of wearable sensors for early detection (Roy, 2017) and the behavior analysis using multimodal sensing (Alvarez, 2018). At this point, our objective in this section is analyze based on the information gathered from the primary sources the general architecture that is being used for the use of IoT in Alzheimer's, for then identified how these solutions can add their functionality for cognitive reinforcement process. IoT solutions are mainly focus on determining the cognitive, physical and behavioral parameters of Alzheimer's patients in order to establish normal patterns of recognition of activity (Aitor, 2019). In the Figure 3, we present a flow about the interactions that allow establish the activity recogition in base our literature review. IoT solutions used for Alzheimer's include a set of IoT devices in the phisical space in which the person interacts. In the Figure 4, we present an generic IoT solution that include camera for recognition of the people whom visit to older adult and the send the information of the visitant through of the voice service (Malavasi, 2017) also allow to send photographs stored in the IoT server related for stimulate their memory. The location of sensors will allow tracking of the person related to their daily activities, walking time patterns or detect if the person leaves the physical space. One of the limitations of using cellular networks is the cost of data use, the use of solutions such as LoRA, Sigfox or NB-IoT that are specially designed for IoT can be more efficient for these designs (Sinha,2017), although a possible limitation could be the bandwidth. Figure 5 show the three IoT networks for communication between older adult and care services or family identify in base on literature review. 


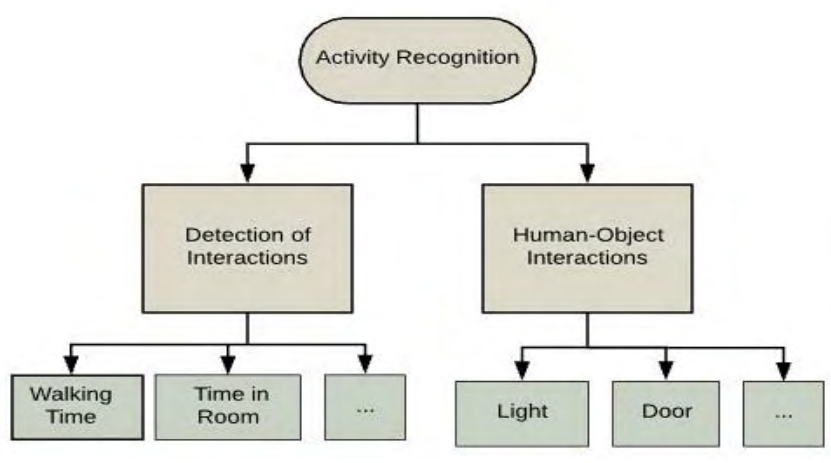

Figure 3. Activity recognition for IoT Alzheimer's solution

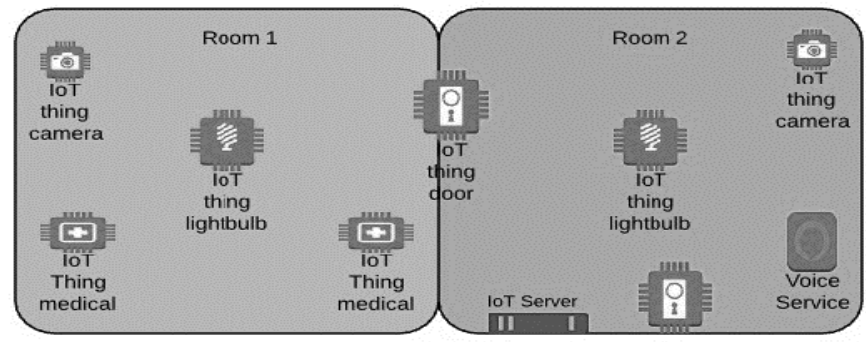

Figure 4. Activity recognition for IoT Alzheimer's design

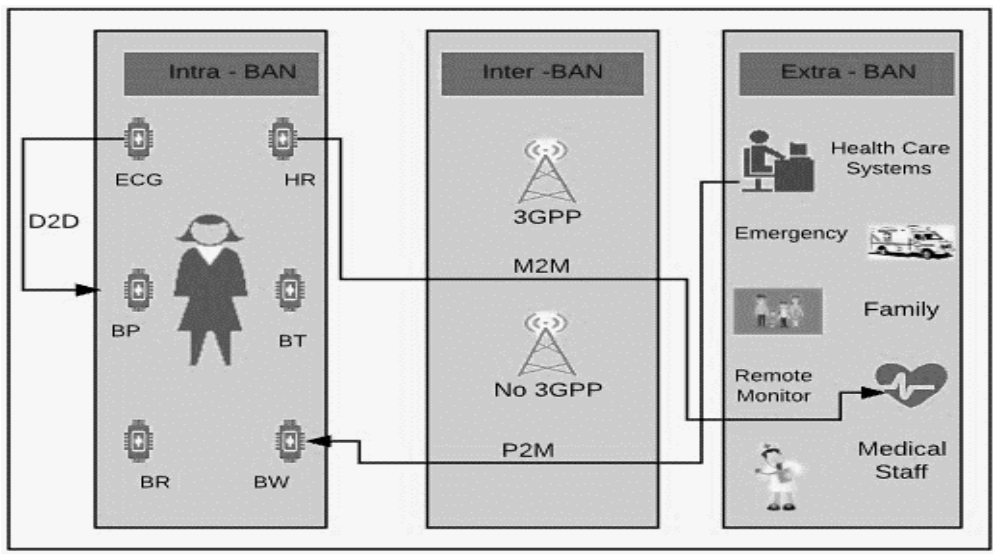

Figure 5. IoT networks for e-health services

The proposed of cognitive stimulation using IoT at present focuses on sending a set of photos, videos and phrases that allow the older adults to keep their memory active; one of the possible drawbacks that could be considered is the use of IoT is their available bandwidth, the delay times, and the privacy issues. We performed a simulation of an IoT environment composed of 16 sensors, with vital signs, video and voice data traffic. Based on the simulation, the bandwidth and delay consumption are not critical, which would allow a real-time interaction between the person with Alzheimer's and the IoT solution for cognitive stimulation. Figure 6, show simulated traffic for 16 sensors send voice, data and video traffic. 


\begin{tabular}{l}
\multicolumn{7}{l}{ Application_metrics } \\
\begin{tabular}{l|l|l|l|l|l}
\hline Application Id & Application Name & Packet generated & Packet received & Throughput (Mbps) & Delay(microsec) \\
\hline 1 & App1_SENSOR_APP & 100 & 100 & 0.000400 & 4262.400000 \\
1 & App1_SENSOR_APP & 100 & 100 & 0.000400 & 4262.400000 \\
1 & App1_SENSOR_APP & 100 & 100 & 0.000400 & 4262.400000 \\
1 & App1_SENSOR_APP & 100 & 100 & 0.000400 & 4262.400000 \\
1 & App1_SENSOR_APP & 100 & 100 & 0.000400 & 4262.400000
\end{tabular}
\end{tabular}

Figure 6. Sensor Data in IoT simulation

The results in the Figure 7, show that the inclusion of encryption protocols to ensure the privacy of information of the older adult generate greater increase in delays, so this is a possible reason for which some IoT solutions are not used; we performed a simulation in the same environment indicated above applying AES 128 bits, the results are shown in figure 12, there are no significant increases in throughput or delay, that allow consider their exclusion in the design of IoT solutions.

\begin{tabular}{|l|l|l|l|}
\hline Packet generated & Packet received & Throughput (Mbps) & Delay(microsec) \\
\hline 100 & 100 & 0.000400 & 4262.400000 \\
100 & 100 & 0.000400 & 4262.400000 \\
100 & 100 & 0.000400 & 4262.400000 \\
100 & 100 & 0.000400 & 4262.400000 \\
\hline
\end{tabular}

Figure 7. Data in IoT simulation with AES encryption

\section{CONCLUSION}

The IoT are technological resources that in the field of health allow respond to the diverse demands of patients, through the systems of ambient assisted living (AAL), facilitating the monitoring and control of diseases. We mentioned that Alzheimer's IoT solution could be focus on assisting patients and their families in problems related to memory, helping in the facial recognition of family members, in the geographical traceability of the person and in the detection of behavioral patterns and symptoms through of IoT sensors.

Cognitive stimulation is focus on keeping memory active, the periodic sending of images or sounds that allow establish a memory process could help the person with Alzheimer's reduces the impact of the disease. Through the use of IoT the objective is establish an acknowledgment of the activities of the older adult and based on this recognition send them visual and sound aids. In the scientific field there are few contributions to the moment on how IoT can contribute to the cognitive stimulation of people with Alzheimer's, it is important to emphasize future research in this context.

The third stage of Alzheimer's has symptoms that prevent anyone who performs routine activities with freedom, since that requires the support and care of a third party on a permanent basis, this is a major challenge for the investigation of technologies that may accompany this stage of the disease. IoT allows make important contributions to AAL systems and together with machine learning and BigData can improve the functionalities to improve the quality of life in people with Alzheimer's, so research not only should be focus on solutions for monitoring health, are necessary contributions in compensatory intervention processes.

The incorporation of security mechanisms is important to maintain the privacy of sensitive information, mechanisms must be evaluated so that their incorporation does not generate delays in sending information, algorithms such as AES are quite robust and may not strongly affect the performance of the IoT solution. In this context solutions like blockchain can be interesting for future works. 


\section{REFERENCES}

Aitor Almeida, Rubén Mulero, Piercosimo Rametta, Vladimir Urošević, Marina Andrić, Luigi Patrono, 2019. A critical analysis of an IoT - aware AAL system for elderly monitoring, Future Generation Computer Systems, Volume 97, Pages 598-619.

Aljehani, S. Alhazmi, R. Aloufi, S. Aljehani and R. Abdulrahman, R (2018) "iCare: Applying IoT Technology for Monitoring Alzheimer's Patients," 1st International Conference on Computer Applications \& Information Security (ICCAIS), Riyadh, Medina, Saudi Arabia, pp. 1-6.

Econsultancy.10 Examples of the Internet of Things in healthcare (2019). https://econsultancy.com/internet-of-thingshealthcare.

European Union's Horizon 2020. City4age. www.city4ageproject.eu

Forbes (2019). 14 predictions about the impact of technology's growing presence in health care.

Forbes (2018). Internet of things market to reach $\$ 267 \mathrm{~b}$ by 2020. https://www.forbes.com.

Health World Organization, HWO. Metal disorders (2019). https://www.who.int/es.

Kerchner, G. A. \& Wyss-Coray, T. The Role of Aging in Alzheimer's Disease, 197-227 (Springer International Publishing, Cham, 2016).

Malavasi, M. et al. An innovative speech-based interface to control aal and iot solutions to help people with speech and motor disability. Ambient Assist. Living. ForItAAL 2016. 426, 269-278 (2017).

Medrano-Gil, A. et al. Definition of technological solutions based on the internet of things and smart cities paradigms for active and healthy ageing through cocreation. Wirel. Commun. Mob. Comput. 1-15, DOI: 10.1155/2018/1949835 (2018).

Mulero, R. et al. An iot-aware approach for elderly-friendly cities. IEEE Access 6, 7941-7957, DOI: 10.1109/ACCESS. 2018.2800161 (2018).

Muñoz E. Estimulación cognitiva y rehabilitación neuropsicológica. (2009). Editorial UOC.

Navarro, J., Doctor, F., Zamudio, V., Iqbal, R., Sangaiah, A. K., \& Lino, C. (2018). Fuzzy adaptive cognitive stimulation therapy generation for Alzheimer's sufferers: Towards a pervasive dementia care monitoring platform. Future Generation Computer Systems, 88, 479-490. doi: 10.1016/j.future.2018.06.018

North Caroline State Center, NCSC. Health Statistics (2019). https://schs.dph.ncdhhs.gov.

Portellano, J, 2005, Introducción a la Neuropsicología, McGRAW-HILL/Interamericana de España, S. A. U, Madrid.

Roadmap. (2019). https://roadmap-alzheimer.org.

Roy, N, 2017, Wearable and IoT for cognitive health assessment: Significance and challenges, IEEE International Conference on Pervasive Computing and Communications Workshops (PerCom Workshops), Kona, HI, pp. 660-660. doi: 10.1109/PERCOMW.2017.7917641

Sinha, R., Yiqiao, W. \& Hwang, S.-H. A survey on lpwa technology: Lora and nb-iot. ICT Express 3, DOI: $10.1016 /$ j.icte. 2017.03 .004 (2017).

Timeless (2019). https://www.timeless.care

Trendmicro. Patients and privacy: GDPR compliance for healthcare organizations. (2019). https://www.trendmicro.com/

Tsirmpas, C. et al. An internet of things platform architecture for supporting ambient assisted living environments. Technol. Heal. Care. 25, 391-401, DOI: 10.3233/thc-161270 (2017).

Tweri. (2019). http://www.tweri.com/home.aspx

United Nations, ONU. World popular ageing (2018). https://www.un.org.

United Nations, ONU. Global issues ageing (2018). https://www.un.org

Zhu, N. et al. Bridging e-health and the internet of things: The sphere project. IEEE Intell. Syst. 30, 39-46, DOI:10.1109/MIS.2015.57 (2015). 